\title{
Los talleres de teatro comunitario: construyendo el diagnóstico socio cultural del barrio San Benito desde los cuerpos, sentires y voces de las y los vecinos de la comunidad educativa del Secundario $N^{\circ} 41$ "Osvaldo Bayer" de Río Gallegos
}

\section{Communal theater workshops: building the social and cultural diagnosis of San Benito 's neighborhood, from bodies, feelings and voices of all the neighbors of the community of secondary school number 41 'Osvaldo Bayer' in Rio Gallegos}

\author{
Carla Daiana Cienfuegos, Natalia Michniuk \\ cienfuegos437@gmail.com,nataliamichniuk@yahoo.com.ar \\ Instituto de Educación y Ciudadanía (IEC) Unidad Académica Río Gallegos (UARG) \\ Universidad Nacional de la Patagonia Austral (UNPA) Av. Piloto "Lero" Rivera y \\ Av. Gobernador Gregores, Río Gallegos
}

Recibido: 13/06/2019. Aceptado: 25/10/2019

\section{RESUMEN}

El propósito de este escrito es poder compartir algunos avances de los sentidos educativos de experiencias pedagógicas alternativas que transcurrieron por los bordes de la escuela Secundaria N 41 “Osvaldo Bayer" del Barrio San Benito de Río Gallegos durante el 2016 y 2017, como ser el Proyecto de Teatro Comunitario que hemos coordinado como Equipo de Educación Popular de la UNPA UARG ${ }^{1}$.

Consideramos fundamental poder analizar en esta oportunidad desde este PI 29/A390 UNPA UARG los talleres de teatro comunitario como fuente para el desarrollo del diagnóstico socio cultural del barrio enmarcado en el contexto local y provincial. Nuestra elección metodológica general es la IAP vinculada a la EP desde una perspectiva crítica. El recorte seleccionado para este informe, se basa en la sistematización de los talleres compartidos con los y las vecinas, que fueron -y siguen siéndolo- parte de la estrategia metodológica y de las técnicas de recolección de información.

Palabras clave: Teatro comunitario; educación popular; prácticas educativas contrahegemónicas; sistematización.

\footnotetext{
${ }^{1}$ Proyecto de Extensión "Educación Popular y teatro comunitario. Una experiencia en el Barrio San Benito de Río Gallegos" (desde el 2016 y continúa) (Acuerdo de Unidad 656/16) Dirección: Mg Natalia MichniukProyecto seleccionado por:

* la SPU- Convocatoria de proyectos de Extensión Universitaria 2017 “ Universidad , Cultura y Sociedad" ha resultado seleccionado por Resolución RESOL-2017-5135-APN-SECPU\#ME y

* por la convocatoria de Proyectos de Extensión UNPA 2018 Resolución N ${ }^{\circ}$ 133/17- CS-UNPA enmarcado en nuestro Programa Institucional "Problemáticas Educativas: Formación e intervención desde una perspectiva crítica” Acuerdo de Unidad 924/10 UNPA-UARG (desde 2010 y continúa). Dirección: Mg Natalia Michniuk
} 


\begin{abstract}
The purpose of this writing is to be able to share some advances of the educational senses of alternative, pedagogical experiences that passed by the edges of the secondary school $\mathrm{N}^{\circ} 41$ "Osvaldo Bayer" (of the neighborhood San Benito from Río Gallegos during the 2016 and 2017), as being the Community theatre project, that we have coordinated as a Popular Education Team the UNPA UARG ${ }^{2}$.

We consider it essential, to analyze this opportunity from this PI 29/A390 UNPA UARG the community theater, workshops as a source for the development of the socio-cultural diagnosis of the neighborhood framed in the local and provincial context. Our General methodological choice is the IAP linked to PD from a critical perspective. The cut selected for this report is based on the systematization of the shared workshops with the neighbours, who were-and still are-part of the methodological strategy and information collection techniques.
\end{abstract}

Key words: Community Theatre; Popular education; counterhegemonic educational practices; systematization.

\title{
1. INTRODUCCIÓN
}

Al pensar en propuestas educativas "contra hegemónicas" que transitan no solo dentro del Secundario $\mathrm{N}^{\circ} 41$ sino también por sus bordes, la experiencia del taller de teatro comunitario conformó durante el 2016 -que fue su inicio- y 2017 una actividad concreta compartida con los/as vecinos/as, personal de la Escuela y algunos/as estudiantes de la comunidad educativa de dicha institución. Si bien el año de beca de una de las autoras de este escrito fue el 2018 la sistematización de las experiencias de estos dos años anteriores fueron y son fundamentales para la escritura de este artículo ${ }^{3}$.

Desde la perspectiva de la Investigación Acción Participativa hay un intento de lograr instancias de participación de y con la comunidad educativa con la que no solo hemos compartido los talleres de teatro comunitario sino también aquellas prácticas que estamos vivenciando en trabajo conjunto con esta Escuela. Al respecto y sabiendo que escapa a los objetivos de este escrito, queremos señalar que lo vivenciado en los talleres de teatro comunitario en el período señalado se nutrió y a la vez aportó al trabajo con los/las docentes y estudiantes de esta Escuela. Como ejemplos concretos podemos mencionar la participación y colaboración en la materia "Proyecto de intervención socio comunitaria" a cargo de la Profesora Lucrecia Vivanco, donde en los encuentros que compartimos pudimos ser parte en un doble sentido, ya que por un lado fuimos entrevistados por estudiantes de este materia, como actores partícipes de actividades que se realizan en el mismo (los talleres de teatro comunitario) y por el otro lado acompañamos el proceso de este grupo de estudiantes y

\footnotetext{
${ }^{2}$ Extension project "Popular Education and community theatre. An experience in the neighborhood San Benito of Río Gallegos "(from 2016 and continues) (Agreement of Unit 656/16) management: Mg Natalia MichniukProject selected by:

* The SPU-call for projects of university extension 2017 "University, Culture and society "has been selected by resolution RESOL-2017-5135-APN-SECPU \# ME and

* By the call for extension projects UNPA 2018 resolution $\mathrm{N}^{\circ}$ 133/17-CS-UNPA framed in our institutional program "Educational problems: training and intervention from a critical perspective" Unit Agreement 924/10 UNPA-UARG (from 2010 and Continues). Management: Mg Natalia Michniuk.

${ }^{3}$ Cabe destacar que durante el año donde transcurrió la beca de la estudiante Cienfuegos, se sostuvo el taller de teatro comunitario en el comedor Red de Mujeres Solidarias donde participan algunas de las madres de estudiantes del secundario donde se compartió los inicios del proyecto de extensión en cuestión.
} 
profesora en la elaboración de estrategias y dispositivos para llevar a cabo intervenciones concretas en el territorio para trabajar una problemática puntual elegida por ellos: la falta de alumbrado público.

Consideramos que el lenguaje -en este caso el teatral comunitario- es el resultado de un devenir histórico, es el hecho social de la interacción verbal/corporal que no sólo codifica el contexto, sino también lo decodifica; que no sólo denuncia, sino que también anuncia, construye, crea otras realidades posibles. Posicionándonos desde esta perspectiva crítica, preocupadas y preocupados por repensar experiencias educativas que se acerquen a otros formatos escolares que no sean hegemónicos, emerge nuestra propuesta como Equipo de Educación Popular de compartir el taller de teatro comunitario ${ }^{4}$ entonces como una posible herramienta generadora a mediano y largo plazo de prácticas, experiencias y procesos que colaboren con el empoderamiento de los/as vecinos/as de esta comunidad educativa de la Escuela Secundaria N ${ }^{\circ} 41$ "Osvaldo Bayer" del barrio San Benito.

Una de las tareas fundamentales en el marco del Plan de trabajo de la Becaria Cienfuegos, fue no sólo participar de la coordinación de alguno de los talleres de teatro comunitario en la Escuela, sino también ser parte del proceso de planificación y sistematización de estas actividades, privilegiando desde el campo psicopedagógico su mirada clínica, su concepción sobre el aprendizaje, sus aportes para la colaboración de un sujeto colectivo. Este análisis elaborado desde la sistematización de los registros realizados de cada taller compartido, nos brinda fundamentalmente elementos para la necesaria elaboración dentro del PI del diagnóstico del contexto barrial, enmarcado claro está en el actual contexto de crisis regional/nacional/provincial y local. Desde esta perspectiva, el análisis crítico de las diversas actividades llevadas a cabo en esta Escuela -específicamente los talleres de teatro comunitario en esta oportunidad- nos permite generar el material necesario para poder concretar en lo inmediato una sesión de retroalimentación con la comunidad con la que estamos trabajando y de esta manera ver como las y los vecinos, integrantes de la comunidad educativa en cuestión se incorporan a la construcción de conocimiento relacionada a los objetivos de este PI.

Consideramos que los resultados de este PI, específicamente en lo que concierne a la sistematización participativa de las actividades compartidas con la comunidad educativa en cuestión, favorecerán a la reflexión y análisis crítico de las experiencias pedagógicas alternativas que transcurren en los bordes de la escuela del Barrio San Benito de Río Gallegos por parte de sus protagonistas, identificando los aspectos educativos reproductores y o de

\footnotetext{
${ }^{4}$ Desde el año 2013 junto a un grupo de mujeres del barrio del Bicentenario de Río Gallegos -lindero al Barrio San Benito- se constituyó desde el Equipo de Educación Popular un espacio en el cual se abordaban temas específicamente referidos al cuidado de su salud sexual y reproductiva, a medida que se iba constituyendo y construyendo el vínculo este grupo comenzó a desarrollar identidad, pertenencia, ampliando su inserción en el territorio. Así nace Karken Aike coordinado por la Lic Patricia Blanco y con la colaboración de la Mg Natalia Michniuk. Lo que inicialmente fue un tema de salud, continuó ampliándose a otras condiciones concretas de existencia. Durante los encuentros en estos talleres se pudo visualizar los cambios subjetivos en relación al posicionamiento del propio cuerpo, la necesidad de mover-se, de expresar mediante el cuerpo, de preguntar y preguntar-se, de tomar la palabra, de comunicarse, de expresar mediante técnicas de la metodología participativa lo que les pasaba como sujetos generalmente acallados, silenciados. Se manifestaba en cada uno de los encuentros el grado de pertenencia como grupo, y el deseo de poder lograr desde lo colectivo, un propio discurso que de cuenta del "nosotros". Es por ello, y respondiendo a demandas propias de estas vecinas, que se pensó el proyecto de Teatro comunitario desde la Educación Popular. Esta nueva propuesta comenzó a vivenciarse en las instalaciones de la Escuela Secundaria $N^{\circ} 41$ en el año 2016, proponiendo a la tallerista municipal Silvina Vilanova para que nos acompañe en la coordinación. Se materializará de esta manera, una relación directa con la Dirección de Cultura de la Municipalidad de Río Gallegos, iniciando la conformación de un grupo de trabajo interinstitucional.
} 
resistencia que prevalecen, así como los sentidos educativos que tienen para los actores/actrices involucrados/as. Hemos vivenciado a partir de las actividades anteriormente mencionadas y otras que durante todo el 2018 y actualmente también estamos coordinando, la importancia del intercambio y convivencia de saberes, de experiencias, sentidos y propuestas entre el equipo de investigación y la comunidad educativa de la escuela media de referencia, sabiendo que la construcción de conocimiento desde la IAP implica en este caso no sólo analizar crítica y situadamente los procesos educativos que se van desarrollando, sino también generar propuestas en conjunto que permitan una transformación superadora de la realidad que se presenta injusta, opresora.

En lo que concierne específicamente a la formación de grado de la becaria desde la carrera de Lic. en Psicopedagogía, sabemos que en la corta historia de creación de esta disciplina, fue fundada para responder a las demandas vinculadas a los problemas de aprendizaje generadas en ámbitos de educación denominado formal y el área de discapacidad, supeditando su objeto de estudio al sujeto en situación de aprendizaje. Consideramos que el ámbito de intervención de la psicopedagogía en la actualidad abarca otros campos, y aún así los ámbitos socio comunitarios siguen siendo bastante discriminados desde la intervención y también desde la producción teórica psicopedagógica.

La psicopedagogía debe aportar a poder problematizar la lectura, el análisis de la realidad colaborando con los distintos grupos sociales, interpelando las condiciones objetivas que condicionan los procesos subjetivos. Esta práctica dentro del campo comunitario como área de vacancia que nos convoca, se apoya también en la mirada clínica, que busca ofrecer nuevas formas de pensar, de sentir con otros y otras, de hacer y movilizar procesos de aprendizaje en, de y a partir de la realidad, los cuales implican necesariamente una reflexión crítica de la misma, una reflexión colectiva. Creemos muy oportuno en estos contextos de crisis y persiguiendo los propósitos anteriormente mencionados, poder sostener la propuesta del taller de teatro comunitario, habilitando desde el arte una manera de denunciar pero también de anunciar otras realidades posibles, deseables, imaginadas.

Consideramos entonces que la psicopedagogía podría constituirse en una herramienta para colaborar en los procesos comunitarios de resistencia, concientización, diálogo, comunicación, habilitando prácticas sociales donde los sujetos puedan posicionarse desde la reflexión crítica, la autoría, la creatividad. Estos procesos, que son de transformación, podrían desde el campo psicopedagógico ser impulsados a partir sobre todo del rescate y valorización del aprendizaje como herramienta fundamental y necesaria para lograr cambios, mejoras, herramienta para poder desde la construcción de un sujeto colectivo pensar, imaginar y porqué no luchar por inéditos viables. Y esta lucha no sólo se vivencia desde la acción sino también desde la reflexión, desde el hacer, pero también desde el pensar. En este sentido la intervención psicopedagógica es "praxis".

\subsection{MARCO HISTORICO}

A lo largo de estos últimos once años nos hemos ido conformando como grupo de trabajo, que desde la Universidad desarrolla su tarea de investigación, formación de grado y extensión con una mirada integral y con un posicionamiento crítico, entendiendo al conocimiento como construcción colectiva en la que se ha privilegiado, y se privilegia, el desarrollo de espacios de participación horizontal con la comunidad, ponderando como protagonistas a los distintos actores de organizaciones barriales, colectivos, escuelas. En esta construcción dialógica son 
los aportes, experiencias, vivencias, saberes, conocimientos de todos los involucrados los que posibilitan la materialización de la co-producción.

Desde la integralidad ${ }^{5}$ de nuestra tarea, nos nuclea el Programa Institucional de la UNPAUARG (desde 2010 y continúa) "Problemáticas Educativas: Formación e intervención desde una perspectiva crítica" estructurado alrededor de dos ejes: "Educación y formación desde una perspectiva crítica", pensado para desarrollarse en el campo de la denominada educación formal, y "Educación Popular desde una perspectiva crítica", para ser desarrollado en el campo socio-comunitario en sentido amplio. Actualmente en este Programa se inscribe el Proyecto de Extensión "Educación Popular y teatro comunitario. Una experiencia en el Barrio San Benito de Río Gallegos" y se vincula con el Proyecto de Investigación 29/A390 UNPA UARG (2017 y continúa) "Análisis crítico de los sentidos que tienen diversas experiencias pedagógicas alternativas que transcurren por los bordes de una escuela del barrio San Benito de Río Gallegos. Continuidades y resistencias de la cultura hegemónica. Aportes y abordajes desde la EP y la IAP”, ambos dirigidos por la Mg Natalia Michniuk.

Creemos importante resaltar en este apartado de nuestro marco histórico como Equipo de Educación Popular de la UNPA UARG que nuestros Proyectos de Investigación desde el 2011 se centran en esta elección política, pedagógica y metodológica por la IAP y la EP, a saber: período 2011-2013: PI 29/ A268-1 UNPA UARG: "La educación popular, una alternativa pedagógica-política en los actuales escenarios. Posibles articulaciones con el Sistema Educativo Formal" dirigido por la Mg. M. Laura Acconcia; período 2014- 2016 PI A 29/311 UNPA UARG "La educación popular, una alternativa político-pedagógica para la problematización y transformación de nuestras prácticas. Sistematización participativa de experiencias educativas y socio-comunitarias en la ciudad de Río Gallegos". dirigido por la Mg. M. Laura Acconcia.

A lo largo de estos años el equipo de trabajo ha participado y participa también de distintos eventos académicos nacionales e internacionales, de Jornadas de y con educadores y educadoras populares, ha organizado Jornadas y paneles de educación popular con participación activa de grupos de distintos colectivos, organizaciones, etc, estudiantes, docentes del denominado sistema educativo formal, egresados de nuestra Universidad y profesorado universitario (tanto local como de otras provincias). Hemos organizado seminarios de Postgrado, hemos sostenido y seguimos compartiendo talleres, círculos de lectura, paneles, charlas debates en distintos territorios, tanto en nuestra localidad como en otras ciudades de la Provincia de Santa Cruz y de otras jurisdicciones, destacándose que algunos talleres han sido y son parte de proyectos con frecuencia semanal en barrios durante ciclos prolongados.

Se vivencia y caracteriza de esta manera estos espacios, como espacios pedagógicos de formación que implican una convivencia, horizontalidad y dialogicidad de saberes, donde el territorio puede ser el propio campus de la Universidad o los mismos barrios, las escuelas y comunidades con las que trabajamos, llegando a vislumbrar posibilidades de otras prácticas pedagógicas que procuramos resulten contrahegemónicas.

Producto de los intercambios con otros equipos de investigación de Universidades Públicas vinculados a la Investigación Acción Participativa (IAP) y a la Educación Popular (EP) pertenecientes no sólo a la Argentina, como la UBA (dirigido por la Dra Llosa) y la UNJu

\footnotetext{
${ }^{5}$ Para ampliar en el concepto, ver Tommasino, H. y Cano, A. (2016) “Avances y retrocesos de la extensión crítica en la Universidad de la República de Uruguay”. En Revista Masquedós. № 1, Año 1, pp. 9-23. Secretaría de Extensión UNICEN. Tandil, Argentina
} 
(dirigido por la Mg Villagra), con trayectoria reconocida y producción en este campo, sino también del Brasil , como la Universidade Federal Do Rio Grande UFRG (dirigido por el Prof. Thum), este equipo trabajó en la conformación de una Red de Investigación Acción Participativa y Educación Popular de universidades Públicas (RIAPEP), la que finalmente se formalizó en el $2016^{6}$

Vincular nuestras praxis en investigación y la denominada extensión, propicia instancias de retroalimentación permanente con la comunidad, basadas en el posicionamiento que entiende que el trabajo, las tareas y las actividades universitarias no pueden considerarse como prácticas aisladas, alejadas de la comunidad, sino que se conciben y concretan desde una integralidad y en territorio. Esta integralidad se aborda desde una mirada interdisciplinaria, de la que las formaciones de los integrantes del equipo dan cuenta (tanto como docentes investigadores, egresadas y estudiantes): pedagogas, psicopedagogos/as, licenciadas en enfermería y también se suman los saberes y experiencias de los otros actores con los que se interactúa en las distintas actividades propuestas: docentes de nivel medio, estudiantes, vecinos y vecinas, referentes barriales, entre otros ${ }^{7}$.

\subsection{MARCO TEORICO}

\section{A-LOS SENTIDOS DE LA EDUCACIÓN. BREVE RECORRIDO HISTÓRICO}

El mandato fundacional de las escuelas creadas en la modernidad era la formación del ciudadano para su integración en la vida pública y en el mundo del trabajo como productor activo, garantizando el nuevo orden asentado en la idea de razón y progreso. Éste era el sentido que se le asignaba y asumía la educación desde fines de s. XIX a pasada la mitad del s.XX

El discurso de la modernidad propiciaba a través del proceso de secularización de la escuela una organización racionalista de la sociedad que produciría empresas productivas eficientes y aparatos del Estado que juntos afianzarían el progreso provocando el bienestar universal. Varios autores han analizado el quiebre de este mandato fundacional y del formato de las instituciones educativas creadas en la modernidad que ya no pueden responder a los requerimientos de los nuevos escenarios. Escenarios signados por las consecutivas transformaciones del rol del Estado llegando a la desresponsabilización de garante de los derechos civiles, los cambios en el mundo de la producción y del trabajo, las innovaciones producidas por las nuevas tecnologías de la información y la comunicación junto a las preeminencias de lógicas del mercado en un mundo globalizado han modificado las coordenadas que enmarcaron a las instituciones modernas y a las subjetividades que allí se constituían (Linás:2011:129). Estos factores han provocado un debilitamiento de los lazos solidarios con una ruptura del tejido social y un aumento de la exclusión y desigualdad social, una crisis de participación ciudadana, modificando las relaciones sociales, y los vínculos intergeneracionales y los modos en que se produce y circula el saber. Asistimos a una crisis de participación y ciudadanía.

\footnotetext{
${ }^{6}$ RIAPEP (Red de Investigación Acción Participativa y Educación Popular en Universidades Públicas) Formalizada mediante Acuerdo de Unidad 863/16 UNPA UARG

${ }^{7}$ Parte de este apartado pertenece a la ponencia "Problemáticas Educativas: formación e intervención desde una perspectiva crítica. El desafío de la integralidad desde un Programa Institucional de la UNPA UARG" presentada en el Primer Congreso Internacional de Educación e Inclusión desde el Sur organizado por el Municipio de Río Grande y UNISAL Río Grande, Tierra del Fuego 18,19 y 20 de octubre de 2018
} 
Ahora bien, el ideal de formar un ciudadano libre y autónomo a través de la educación escolar, ha fracasado, y como señala Rigal, (2004) constituye una asignatura pendiente a ser resuelta en cualquier proyecto de futuro. Este autor junto a varios más sostienen que estamos viviendo un momento de crisis en el profundo sentido gramsciano donde lo viejo está agonizando o muerto y lo nuevo está por venir o aún no ha nacido. La muerte de lo viejo terminó con las viejas certezas, los grandes relatos de la modernidad donde el futuro era visto como una promesa y generó un sentimiento de incertidumbre, en el que el futuro es visto como una amenaza. Asistimos también a un momento de fragmentación, donde la realidad se ha trizado y no se percibe cómo recomponerla.

Una de las manifestaciones de la crisis es la imposibilidad de pensar en el porvenir, en vislumbrar que otro mundo es posible. La fragmentación se manifiesta en sujetos sociales profundamente diferentes y en situación de extrema desigualdad, relacionados pero no articulados entre sí, recompuestos en un espacio ideológico común hegemonizado por el modelo dominante que aún asigna a la escuela un relevante papel, si bien no exclusivo, de transmisora de esa hegemonía. Dentro de este escenario, la crisis, la incertidumbre y la fragmentación, atraviesan el campo educativo determinando buena parte de los discursos actuales, que interpelan también el sentido o los sentidos de la educación. La crisis de la educación, siguiendo a Rigal, es una crisis de sentido donde la cuestión central de carácter ético es qué significa que la escuela eduque.

Ampliando este interrogante y el campo educativo donde se construyen y configuran diversos sentidos educativos, pensamos que no sólo es una cuestión ética sino también política el interrogarnos acerca de ellos, lo que nos guiará en el análisis crítico de diversas experiencias pedagógicas alternativas que circulan por los márgenes de las escuelas. Durante la década de los 90, se implementaron distintas reformas educativas en América Latina a fin de mejorar la calidad educativa y abordar la crisis de la educación, en nuestro país la encarnó la Ley Federal. El fracaso de estas reformas fue analizado como un problema de implementación, fallas instrumentales, pero en realidad la discusión y el balance debiera fundamentarse en el fundamento ideológico de estos proyectos de reforma, en su marco ético - político que lleva a cuestionarnos el sentido adjudicado a la educación. El campo de las reformas es un campo de disputa, de confrontación por la producción de sentidos, por la conformación de una política cultural. La crisis social, ética y política que la década de los 90 dejó en américa latina y particularmente en nuestro país, profundizó el malestar y pérdida de rumbo de las escuelas, lo que generó un campo propicio para la aparición de distintas organizaciones civiles como ONG, planes y programas compensatorios para abordar las desigualdades socio-educativas de los niños y jóvenes que quedaron excluidos o en lugares muy marginados del sistema escolar, con el propósito fundamental de incluirlos e integrarlos al tejido social. Estos procesos de cambios globales que implicaron un desplazamiento de la responsabilidad del Estado hacia individuos, profundizaron las desigualdades en el marco de culturas, de prácticas y de oportunidades.

En su intento por recuperar el orden perdido, las instituciones tradicionales intentan nuevos diálogos con el contexto, con los diversos fenómenos que acontecen en su entorno, con las exigencias ante las nuevas demandas, con las interpelaciones de la que son objeto. Estos procesos modifican su hacer cotidiano, muchas veces desestructuran las creencias y formas de abordar la tarea pedagógica, ponen en crisis su funcionalidad social y con ello su identidad institucional. Este quiebre y pérdida de sentido provoca lo que Tiramonti (2011) llama proceso de forzamiento, tratando de dar cuenta del esfuerzo que las instituciones existentes hacen por mantener el orden y control social y adaptarse a un mundo en crisis. La escuela 
media creada con un objetivo selectivo, no escapa a estas tensiones, ya que esta función selectiva se refleja en la base de su formato y es el fundamento de una cultura escolar que naturaliza la exclusión de aquellos que no pueden responder o adaptarse a las exigencias de la institución. Sin duda los jóvenes provenientes de familias socialmente vulnerables, pertenecientes a sectores desfavorecidos económicamente, poseedoras de un capital cultural distante del exigido por la escuela, serán los que más tempranamente la abandonan.

Estas razones llevaron a los distintos Estados a generar estrategias para implementar tanto dentro de las escuelas con propuestas de cambio en algunos de sus dispositivos para hacer posible una mayor inclusión y disminuir el llamado fracaso escolar, como en espacios reconocidos y denominados bordes, márgenes, frontera de la escuela, y que nosotros identificamos como el "adentroafuera", experiencias alternativas a las prácticas escolares más tradicionales. Estos espacios y cómo se los habita, algunos autores identifican como educación no formal. El campo de lo no formal, un campo que hasta no hace mucho tiempo se sabía más fértil que aprovechado, aparece ahora superpoblado, cada vez más vasto y diverso, asumiendo como puede las necesidades, las demandas y las expectativas sociales que recaen sobre él. (Llinás; 2011:126)

Diferentes propósitos animaron ayer y sustentan hoy la educación no formal de niños, adolescentes y jóvenes; desde espacios más o menos preformateados, bajo muy diferentes formas, con sentidos formativos o no tanto. Ante el desarrollo de actividades en el campo de lo no formal y de políticas centradas en los jóvenes y adolescentes para favorecer su inclusión, debemos puntualizar la representación que se tiene de los jóvenes que generalmente pueblan estos espacios, jóvenes que pertenecen a sectores marginalizados. Su imagen a través de los medios de comunicación se construye desde la carencia, responsabilizados de las problemáticas sociales que afectan al conjunto. Se enfatiza su apatía y falta de interés por participar, por aprender, por trabajar. Se los vincula a la violencia, el delito, las adicciones. Etiquetas que los estigmatizan y discriminan, operando con la fuerza de la profecía autocumplida.

Es importante señalar que no todas las propuestas educativas que tiene lugar en estos espacios están pensadas con un unívoco sentido pedagógico, además por supuesto, de la variedad de sentidos que los actores que participan les adjudican. Sentidos que estarán dados por diversos factores de distinta índole, personal, interpersonal, la significatividad de la propuesta en su forma o contenido, el diálogo o desconexión con el contexto en el que se inscriben. Abordaremos estos espacios, tratando de ir más allá de la nominación de educación no formal, entendiéndolos como experiencias educativas con distintos grados de formalización que se nutren de las distintas áreas de la vida cotidiana (Sirvent, 2009) Puigross (1990) llama experiencias pedagógicas alternativas a aquellos eventos en los cuales se encuentran elementos disidentes o alternativos respecto de lo que se denomina instrucción pública centralizada estatal.

\section{B- REPENSANDO NUEVOS SENTIDOS DE LAS EXPERIENCIAS EDUCATIVAS}

Ahora bien, el sentido que nosotros atribuimos a este tipo de experiencias alternativas, se fundamentan en los principios de la educación popular desde una perspectiva freiriana y se vinculan al concepto de hegemonía que desarrolla Gramsci. Hegemonía y educación para Gramsci. Pilares epistemológicos de la educación popular para Freire.

Gramsci se planteaba también el problema de la educación como un problema esencial en el proceso de elevación cultural del pueblo, que en el período del "Risorgimento" — típico movimiento de élites - había sido descuidado. Pensaba que hacer política no era sólo educar 
a una vanguardia sino tratar de elevar a las masas al nivel de una cultura integral. Y así lo subraya con la siguiente matización: "Crear una nueva cultura no significa hacer sólo individualmente descubrimientos originales, sino también, y especialmente, difundir críticamente verdades ya descubiertas, socializarlas, por así decirlo, y por lo tanto convertirlas en base de acciones vitales, elementos de coordinación y de orden intelectual y social. Sostiene que la supremacía de una clase social no es sólo dominación sino - como hegemonía - dirección intelectual y moral. Para imponerla no basta la coerción — de los aparatos regresivos del Estado - sino que es preciso también el consenso o consentimiento de las clases subalternas. Para el logro de esa hegemonía, es fundamental la función que desempeñan los intelectuales, entre ellos los docentes que actúan como "funcionarios de las superestructura" cimientan la unidad de la estructura y la superestructura, que constituye un bloque histórico determinado, mediante la elaboración y difusión de la ideología de la clase dominante dando lugar a su hegemonía. De ahí la importancia de la educación, ya que ésta desempeña una función esencial en la formación de los intelectuales del bloque emergente como ya lo habían desempeñado en la gestación del bloque dominante. Con la particularidad de que, para los intelectuales del nuevo bloque emergente, la cultura constituye un integrante básico del socialismo, pues éste debe integrar una concepción integral de la vida que comprenda no sólo la organización política sino también la organización del saber a través de la actividad cultural.

El desafío, más bien, es ir del saber al sentir, y del sentir al saber; generar una dinámica dialógica, de praxis colectiva, que combine la reflexión rigurosa y la acción, pero que también se nutra de la experiencia y el sentir popular, en especial de aquellos "núcleos de buen sentido" que anidan en la sabiduría plebeya, así como de los diversos ámbitos que se van cultivando desde abajo y que tienen a lo educativo como un eje central de democratización de la sociedad. A esta vocación de transformación global de la sociedad Gramsci la concebía en los términos de una disputa hegemónica, la cual no puede restringirse a una pelea por demandas corporativas o gremiales, si bien en muchas ocasiones ella suele tener como puntapié inicial a este tipo de exigencias. Para Gramsci, un proyecto hegemónico alternativo involucra la construcción de un sujeto político plural, en donde confluyen diferentes movimientos y grupos subalternos, e implica una apuesta pedagógico-cultural e ideológica, y no solo socio-económica. (Ouviña, 2011).

En consonancia con lo anteriormente planteado, la conceptualización freireana de la educación popular entiende a esta como un proceso constante de codificación y decodificación de la realidad donde todos aprendemos en conjunto mediatizados por el mundo. Las acciones educativas no se restringen al ámbito escolar institucional, sino que toda práctica social es a la vez pedagógica y política. Es así que responde a una intencionalidad, la que muchas veces no es explicitada o de la cual los actores no son conscientes, esto lleva a una naturalización de concepciones o maneras de entender al otro y a nosotros mismos ancladas en posturas dominantes, que terminan tomando al hombre como objeto y no como sujeto. Poder reflexionar sobre esta intencionalidad y hacerla consciente es propiedad del ser humano como tal, historizarse, biografiarse, reconocerse en y con el mundo, inmerso en una realidad concreta a la que puede y, de hecho, transforma con su accionar en interacción con otros sujetos. Es en este sentido que propone una educación problematizadora, reconociendo a la educación en un proceso de comunicacional horizontal, de dialogicidad, que elimina la contradicción 'educador-educando'.

Para Freire, la palabra tiene dos fases constitutivas indisolubles: acción y reflexión. Ambas en relación dialéctica establecen la praxis del proceso transformador. La reflexión sin acción, se 
reduce al verbalismo estéril y la acción sin reflexión es activismo. La palabra verdadera es la praxis, porque los hombres deben actuar en el mundo para humanizarlo, transformarlo y liberarlo. La lectura crítica del mundo significará poder trascender la decodificación ingenua y comprender la complejidad de las relaciones desiguales entre opresores y oprimidos, mediante la concientización. Ésta busca desarrollar una nueva realidad, que gravita en torno a cuatro ejes: el hombre, la historia, la sociedad y el mundo. La educación es comprendida, no como aparato reproductor de la ideología dominante, sino como factor libre-liberador de la conciencia. Con la realidad de que el proyecto no sea meramente utópico, parte de la realidad, dando primacía a la libertad y actuando dentro de la legalidad. La nueva conciencia se caracteriza por ser crítica, política e histórica.

Poder pensar en inéditos viables, permitirá hacer posibles aquellos sueños que cuando se mediatizan desde una praxis liberadora, pasan de la teoría a la acción dialógica, del deseo a la realidad. La educación popular bajo la explicitación de Freire como una "praxis" donde teoría y práctica se amalgaman, no deja de lado la producción de conocimiento, ya que considera esencial esta tarea para el esclarecimiento de las características de los sujetos educativos, de sus contextos, saberes y modos de aprendizaje, así como sobre las propias prácticas educativas y su relación con los movimientos sociales, la cultura y la política. Coincidimos con Apple (1981) en entender a la EP como una teoría de la educación para las clases subalternas, como una propuesta político - pedagógica y sobre todo como una estrategia a ser aplicada en todos los espacios educativos de los sectores populares, más allá de la escuela (convergencia con la concepción gramsciana de hegemonía).

\section{C-TEATRO COMUNITARIO}

El teatro comunitario nace de la voluntad comunitaria, ya sea una región, un barrio o una determinada población, de reunirse, agruparse, organizarse, comunicarse; todo ellos a través del teatro. Partiendo de la premisa que al arte es un derecho de todo ciudadano, y que así como priorizamos la salud, el alimento, la educación, el teatro comunitario propone a la comunidad configurar el arte dentro de las prioridades. Esa inclusión es nuestra tarea, no debemos delegarla en el otro. Debemos concebir el arte como una posibilidad de pensar y crear nuevas realidades.

Es importante recordar que el arte es un agente de transformación social, con la profunda convicción de que toda persona es esencialmente creativa. Al organizar un marco acorde, como el del teatro comunitario, esa creatividad encontrará un espacio armónico y cuidado para que comience a fluir, comience a expresarse; rehabilitando así al sujeto en sus posibilidades de ser creativo.

Volviendo a centrarnos en los aportes del campo psicopedagógico a estas reflexiones, consideramos que a través de esta herramienta de transformación social como lo es el teatro comunitario, el sujeto puede desplegar su creatividad y poner en palabras y en escena su acontecer, siendo de esta manera autor/relator de este acontecer. Como expresáramos anteriormente, el contexto de grave crisis local, era protagonista en nuestros encuentros. En todos los talleres compartidos con los y las vecinas del Barrio San Benito, y a partir de las actividades propuestas en nuestra planificación como coordinadores, surgían dramatizaciones donde se representaba lo coyuntural, la bronca, el enojo hacia el gobierno que aparecía materializado por ejemplo a través de la figura de la parka/bruja. Los grupos explicitaban desde las dramatizaciones los reclamos que la ciudadanía y los trabajadores hacen al Estado. 
En los grupos se mostraba la unión de quienes reclaman ante un Estado que es caracterizado como ciego, dando la espalda ${ }^{8}$.

Este tipo de herramienta artística -nos referimos al teatro comunitario- permite soportar con otros y otras esta realidad que muchas veces violenta las subjetividades. Al respecto coincidimos con una de nuestras compañeras del Equipo de Educación Popular cuando cita a Borba (2010) quien analiza que el teatro comunitario es transformador en tanto congrega a vecinos a pensar, compartir, expresar y debatir ideas y acciones de la realidad para encontrar la manera de incidir en ella y originar cambios en forma colectiva. Cumple así una función de rescate de identidades, de encuentros, de comunicación, de recuperar historias del barrio, la ciudad, de lazos sociales y rompe con el aislamiento, la uniformidad y la pérdida de diferencias locales. Nos sumamos a los aportes de este autor cuando invita a pensar que es necesario pronunciarse acerca de las acentuadas e injustas diferencias socio-económicas y utilizar el teatro como herramienta de conocimiento y comunicación para lograr reconstruir la identidad social y cultura fragmentada del barrio, constituyendo un desafío para la recuperación y reconstitución del entramado social resquebrajado por las condiciones del contexto social. En este sentido los talleres en el barrio, han generado un espacio de encuentro entre vecinos donde, a través de las propuestas, se han podido expresar y compartir algunas de las problemáticas complejas de vulnerabilidad que viven cotidianamente, visibilizándolas, debatiéndolas y vivenciando la construcción de un "nosotros". (Ramón, 2018 inédito)

A través del teatro comunitario, el sujeto se puede autorizar a resignificar su realidad, sus condiciones concretas de existencias. La escena al ser dramatizada puede ser vivida como modo de hacer más tolerable, y tramitable la situación que afecta a los sujetos. El dramatizar y la puesta en escena ubica al sujeto en un lugar activo, en un lugar protagónico y aquí podemos traer un nuevo aporte del campo de la psicopedagogía, tal como es lo potencial de la mirada clínica que implica dirigir la atención a las potencialidades del sujeto, preservar el potencial del mismo sin desmentir el obstáculo o problema, lo que permite que este acontecer deje de ser propio y personal para pasar a ser un acontecer de todos y todas, para pensar en comunidad, posibilitando de esta manera un nosotros anunciador de otra/s realidad/es. Poner en evidencia la propia realidad que los/las y nos atraviesa implica un conflicto. Al igual que el aprendizaje como proceso complejo en contante construcción, deconstrucción y reconstrucción. El aprendizaje implica una modificación en los sujetos pero no solo en el propio sujeto sino también en el contexto, en el ambiente y en el entorno que nos rodea.

El teatro comunitario es un proyecto teatral de la comunidad para la comunidad, "(...) no se concibe como un pasatiempo, un lugar de ocio o esparcimiento ni como un espacio terapéutico sino como una forma de producción, un espacio para la voluntad de hacer o construir" (Bidegaín 2007: 33). Sus integrantes se denominan vecinos-actores y son amateurs, ya que no reciben dinero por su trabajo. Los encuentros se llevan adelante en un lugar conocido por todos, ya sea un club, la escuela, la plaza, es decir, un espacio público. Esta autora nos advierte que el teatro comunitario exige y crea una territorialidad particular es así que el Secundario N 41 “Osvalo Bayer" se convirtió durante el 2016 y 2017 en el territorio donde se compartió nuestra propuesta de teatro comunitario.

Los grupos de teatro comunitarios son numerosos, ya que son abiertos a todo aquel que quiera sumarse. Son inclusivos y no exclusivos, debiendo el coordinador del grupo mantener "la puerta abierta" para todos los interesados. No discrimina, ni por edad ni por género. Puede participar un niño de cinco años, así como un adulto mayor de 85 años. Todos tienen un

\footnotetext{
${ }^{8}$ Ver al respecto registro del cuadro II en este escrito
} 
espacio. Y son numerosos, además porque no se trabaja sobre la individualidad del artista, sino en la creencia de que la creatividad se potencia con el otro, revalorizando los saberes individuales en pos de configura saberes grupales. La búsqueda estética aborda la tragedia, tanto como la comedia; pero nunca aborda el drama psicológico. Se busca trabajar lo épico desde lo colectivo, por ello es fundamental que sean muchos los vecinos-actores. "Por otra parte, lo colectivo, además de constituir un abrigo, un ala protectora para comenzar a animarse, potencia la expresividad y genera la pertenencia a un "nosotros" (Scher 2010: 93). El teatro comunitario trabaja el desarraigo, sus orígenes, y al mismo tiempo la realidad del barrio.

Partiendo de lo que es la historia del teatro comunitario, según aportes de Vilanova (2017, inédito) podemos decir que es un "invento argentino". El primer grupo de Teatro comunitario surge en 1983, y es el reconocido grupo Catalinas Sur. En el mismo, los padres del colegio querían hacer teatro y convocaron al director uruguayo Adhemar Bianchi. Comenzaron reuniéndose en la plaza, hoy tienen un espacio propio, un espectáculo en cartel desde hace más de 20 años denominado "El Fulgor Argentino" y son más de 300 vecinos los que forman parte del grupo. En 1996 surge el otro grupo faro del teatro comunitario, El Circuito cultural Barracas coordinado por Ricardo Talento. Este es uno de los tantos casos en el que un grupo de teatro se convierte en un grupo de teatro comunitario. Hoy también tienen un espacio propio. Luego de la crisis del 2001, también surgen gran cantidad de grupos de teatro comunitario.

\section{DESCRIPCIÓN DEL CORPUS Y METODOLOGÍA}

Desde un enfoque cualitativo, en el desarrollo del actual proceso investigativo, la Investigación Acción Participativa (IAP) se presenta ya no como un objetivo o elección, sino como el camino necesario para el logro de los objetivos que como Equipo de investigación de educación popular nos hemos propuesto. Esto en tanto la Educación Popular apunta a la construcción de saberes desde una mirada crítica y transformadora, construcción en la que los sujetos participan de forma activa, aportando desde sus experiencias y prácticas sociales. Coincidimos con Thiollent (1985) cuando refiere a la IAP como una investigación social científica con base empírica, realizada con una preocupación transformadora -esto nos remite a la noción de praxis, noción dialéctica central- en la que investigadores y participantes de una determinada situación problemática se comunican y articulan de modo cooperativo, para avanzar en el conocimiento crítico -conocimiento de ruptura, de superación de lo dado- de una determinada realidad, y proponer cursos de acción transformadora (Thiollent, M. 1985).

Desde esta coincidencia con la visión del papel emancipatorio de la IAP, como modo de hacer ciencia de lo social, en la que se procura la participación real de la población involucrada en el proceso de objetivación de la realidad en estudio (Rigal, L y Sirvent; 2012:14) para nuestro PI tenemos presente las notas características de este modo de investigación:

-Producción de conocimiento con intencionalidad, transformadora (búsqueda, ruptura, cuestionamiento).

-Recuperación de la experiencia práctica de los sujetos involucrados.

-Producción colectiva, en el marco de un encuadre democrático (Rigal, L y Sirvent; 2012:17).

Las experiencias que hemos y seguimos vivenciando con la comunidad educativa de la Escuela Secundaria $N^{\circ} 41$ de Río Gallegos, se enmarcan en la la IAP como eje teórico- 
metodológico. Se pretende así el alcance del triple objetivo que este modo de concebir y hacer investigación persigue:

- Generar conocimiento colectivo, crítico sobre la realidad.

- Fortalecer la organización social y la capacidad de participación de los sectores populares.

-Promover la modificación de las condiciones que afectan su vida cotidiana.

La investigación que elegimos epistémico-política y metodológicamente requiere necesariamente nuestra implicancia personal junto a las y los vecinos del Barrio San Benito y actores/actrices de la comunidad educativa en particular, con las y los que compartimos las experiencias concretas, el proyecto de teatro comunitario es una de ellas. Los talleres compartidos durante los años 2016-2017 fueron analizados mediante procesos de sistematización participativa. La construcción participativa de saberes y la reconstrucción de las experiencias implica la sistematización de las prácticas, esta conlleva a la interpretación crítica de una o varias experiencias, que, a partir de su ordenamiento y reconstrucción, descubre o explicita la lógica del proceso vivido, los factores que han intervenido en dicho proceso, cómo se han relacionado entre sí y por qué lo han hecho de ese modo (Jara; 1994)

Entendemos a la sistematización como una reflexión crítica con propósitos transformadores, la cual favorece tanto proceso de aprendizaje como así también a la construcción social de conocimientos. Por medio de este método se busca producir conocimiento desde la experiencia, conocimiento colectivo, a través del intercambio generar posibles propuestas de transformación, socializar, intercambiar los resultados de la sistematización. Es la oportunidad de construir, de experimentar colectivamente una nueva mirada. Este método y proceso está conformado por momentos que implican un ir y venir, lo cual se vincula fundamentalmente a la perspectiva de la sistematización como proceso flexible. Involucra reconstruir hechos, actividades, cualquier acontecimiento, que esté inmerso en la experiencia de los sujetos con quienes se investiga. Esta reconstrucción de situaciones no se hace en el vacío, entendemos que la problematización de la realidad se contextualiza en tiempo y en espacio debido a que responde a un momento histórico determinado, en un lugar determinado.

Jara (2003) nos propone pasos para lograr este proceso, el primero de ellos es haber vivido la experiencia, en territorio. En este caso en particular la becaria pudo ser parte de los talleres, desde su tarea de coordinadora como también observando y registrando en ocasiones. El acercamiento a la Escuela se realizó previamente como consecuencia de un proceso de trabajo de extensión sostenido en el Barrio, haciendo los acuerdos institucionales necesarios entre Universidad y el Secundario. Se realizaron varias actividades relacionadas al trabajo de campo, como también relevamiento de distintas fuentes para enriquecer la construcción del diagnóstico socio cultural del Barrio. Los registros y su posterior análisis colectivo (sobre todo construido con los y las integrantes del Equipo de Educación Popular y algunos de los participantes de los distintos talleres de teatro comunitario) cobran una relevancia en la elección de la sistematización ya que al definir qué queremos sistematizar y que utilidad le daremos a ese producto, clarifica el sentido del proceso a la vez que habilita la recuperación de la experiencia vivida. Siguiendo con los tiempos que propone Jara, llegar a la reflexión de fondo, significa una verdadera interpretación crítica que aún sigue en proceso de construcción dado que el $\mathrm{PI}^{9}$ donde se inscribe la beca que nos ocupa, sigue en vigencia y recién estamos en la etapa de construcción de síntesis. Esto no implica no poder compartir en este escrito, tal

\footnotetext{
${ }^{9}$ Nos parece importante evidenciar que este proceso de sistematización también se vió relentado por las condiciones vinculadas al contexto nacional/provincial/local, lo cual generó un obstáculo en los encuentros y en el acercamiento al barrio.
} 
como lo estamos haciendo, líneas de análisis, tensiones teóricas desde el campo de la psicopedagogía y de la pedagogía respecto a lo sucedido en estos talleres de teatro comunitario.

Sistematizamos entonces para comprender y mejorar nuestra propia práctica, para extraer sus enseñanzas y compartirlas junto a otros grupos, volviendo nuevamente a la intervención en la realidad. Coincidimos con lo expuesto en el artículo "La Sistematización de Experiencias un método para impulsar procesos emancipadores" (Cepep, 2010) donde se afirma que toda sistematización es construida en un nosotros, es un proceso político debido al carácter transformador, creador, reflexivo, flexible pero sobre todo participativo; el mismo está orientado a la construcción de aprendizajes para pensar en propuestas transformadoras por parte de los actores sociales involucrados protagonistas, generando conjuntamente mediante el análisis e interpretación crítica de esa experiencia un proceso de problematización y reflexión. Estamos en condiciones de afirmar que hemos colaborado -y seguimos haciéndolo- en lograr problematizar junto con la comunidad educativa del Barrio San Benito su realidad concreta.

Decíamos en la introducción de este escrito, que gran parte de esta sistematización es insumo fundamental para la sesión de retroalimentación que compartiremos en breve con la comunidad educativa del Secundario $N^{\circ} 41$. Como explican Sirvent (1999) y Llosa (2017), en las sesiones de retroalimentación se distinguen ciertos momentos, como la presentación de la información obtenida y sistematizada como producto y proceso; la reconversión de la misma a través de la creatividad, culturas y saberes propios de la comunidad con la que se trabaja. Todo este material habilita algunas conclusiones y propuestas innovadoras para continuar con el proceso investigativo.

\section{RESULTADOS, ANÁLISIS Y DISCUSIÓN}

En el marco del PI que nos ocupa, se desarrolla el proyecto de Extensión "Educación Popular y teatro comunitario. Una experiencia en el Barrio San Benito de Río Gallegos". Esta experiencia empezó a compartirse con vecinos, vecinas y algunos/as integrantes de trabajadores y estudiantes de la Escuela los días sábados desde octubre del 2016 hasta finales del 2017 con una frecuencia promedio quincenal en la Escuela Secundaria $N^{\circ} 41$ "Osvaldo Bayer" de Río Gallegos. La escuela se abre a nuestra propuesta, propiciando de esta manera no solo un lugar material sino también simbólico, no casualmente en los talleres aparecen representaciones de la misma como un "espacio de encuentro". Cada encuentro sirvió para visibilizar y pensar de forma colectiva cuáles eran/son las problemáticas puntuales que atraviesan la cotidianeidad de los/as vecinos/as. Fueron los/as propios/as protagonistas de este espacio coordinado por el Equipo de Educación Popular, quienes a través de la metodología participativa y dramatizaciones expresaron cuáles eran sus necesidades, las problemáticas que los afectan cotidianamente, sus deseos, sus sueños. Se evidenciaba sábado tras sábado, el grado de solidaridad, pertenencia e identidad barrial que existe -o no- entre los/as vecinos/as; las condiciones de vulnerabilidad social en las que viven; etc.

Previo a los talleres de los días sábados, se planifica rigurosamente cada encuentro, siendo la sistematización del encuentro anterior, pieza fundamental para este objetivo. Estas planificaciones a su vez responden al contexto, a la coyuntura social, económica, política de la ciudad y abren/habilitan el espacio para que los y las vecinos y vecinas, docentes, estudiantes puedan expresarse, puedan evidenciar y poner en tensión la realidad que nos/los y las atraviesa. Resulta una tarea fundamental considerar como insumo de trabajo, el análisis de los 
registros de observación que surgen a partir de cada taller. Al analizarlos, las situaciones que emergen desde los y las participantes se relacionan con sus condiciones de vida, la precariedad, la intencionalidad de sobrevivir y cómo los traviesa directamente la crisis del contexto provincial/nacional. A partir de las observaciones, del análisis de los registros podemos afirmar que se generaron espacios de participación que permitieron a los vecinos visibilizar y pensar colectivamente cuales son las cuestiones cotidianas del barrio que los atraviesan. Surge así, la necesidad de problematizar la situación que están viviendo, donde se preguntan cómo está hoy el barrio, la ciudad y la provincia (Ramón, 2018 inédito)

Seleccionamos algunos de los talleres que consideramos fueron significativos para la sistematización de los mismos y para el desarrollo de este escrito.

Cuadro 1 (parte del registro realizado del encuentro del 20 de octubre del 2016)

\begin{tabular}{|c|c|c|}
\hline Registro & Implicación & Categorización \\
\hline $\begin{array}{l}\text { DINAMICA CON GLOBOS: } \\
\text { 17:45 hr dinámica con globos. } \\
\text { Se propone dividir el espacio en } \\
\text { dos, una que sería } \\
\text { simbólicamente el escenario y el } \\
\text { otro el lugar del espectador. En } \\
\text { el "escenario" dejamos globos } \\
\text { para que los y las participantes } \\
\text { interactúen con estos y } \\
\text { modifiquen su acción } \\
\text { dependiendo la consigna. }\end{array}$ & $\begin{array}{l}\text { En esta actividad se pone a prueba, } \\
\text { como siempre mi velocidad de } \\
\text { reacción, mi adaptación al grupo. } \\
\text { Me divierte a veces, ser lenta, lo } \\
\text { disfruto, no es así en las actividades } \\
\text { competitivas, donde la externa } \\
\text { espera de mí, cierto asertividad. } \\
\text { Disfruto la actividad, exploro } \\
\text { niveles y lugares no convencionales } \\
\text { de impulso del globo, pero jugando } \\
\text { a veces, no cumplo con algún } \\
\text { aspecto de la consiga. También } \\
\text { estoy atenta a no dejar espacios } \\
\text { vacíos, eso hace que a veces este } \\
\text { lejos de la acción principal. } \\
\text { Me sentí espectadora, no tuve } \\
\text { mucha participación. Pero me gusto } \\
\text { poder observar desde afuera. }\end{array}$ & $\begin{array}{l}\text { Poner el cuerpo. } \\
\text { Cooperacion. } \\
\text { Apoyo grupal. } \\
\text { Sentido de } \\
\text { grupalidad. } \\
\text { Trabajo colectivo. } \\
\text { Singularidad de los } \\
\text { participantes. } \\
\text { Concepción del } \\
\text { uso del espacio } \\
\text { teatral. } \\
\text { Creatividad. } \\
\text { Sostén } \\
\text { Disfrute. Sujeto } \\
\text { activo, interacción, } \\
\text { intercambio }\end{array}$ \\
\hline $\begin{array}{l}\text { 18:00 hs REFLEXIÓN } \\
\text { En el momento de la reflexión } \\
\text { surgen algunos comentarios de } \\
\text { ambos grupos como: } \\
\text { "estábamos re desordenados", } \\
\text { "si participamos todos", } \\
\text { "estaban re contentos aunque no } \\
\text { fue esa la consigna", "seguían el } \\
\text { objetivo a rajatabla me pareció, } \\
\text { seguían una meta", "algunos } \\
\text { hacían trampa, no se podía usar } \\
\text { las manos y algunos la usaban } \\
\text { igual"; "nosotros a diferencia de } \\
\text { ellos usamos más el cuerpo si } \\
\text { teníamos que usar la panza }\end{array}$ & $\begin{array}{l}\text { Entre las tantas preguntas que hizo } \\
\text { A., surge una que me hizo reforzar } \\
\text { lo que había pensado. "¿Qué } \\
\text { tuvieron en común ambos grupos?". } \\
\text { Noto una cierta emoción por parte } \\
\text { de algunos por responder "EL } \\
\text { TRABAJO EN EQUIPO",EL } \\
\text { ENTUSIASMO", } \\
\text { DIVERSION" } \\
\text { Es increíble cómo se vive la misma } \\
\text { situación vista desde afuera/adentro. } \\
\text { Desde afuera veo que lo que un } \\
\text { grupo decía sobre el otro grupo } \\
\text { acerca de que éste hizo trampa, } \\
\text { percibo que éste primero también lo }\end{array}$ & $\begin{array}{l}\text { Interacciones, } \\
\text { Meta cognición. } \\
\text { Auto percepción. } \\
\text { Organización } \\
\text { grupal. Objetivo } \\
\text { colectivo } \\
\text { Sensaciones } \\
\text { compartidas y no } \\
\text { compartidas. } \\
\text { Sostén. } \\
\text { Espacios } \\
\text { simbólicos } \\
\text { Expresión, trabajo } \\
\text { en equipo. }\end{array}$ \\
\hline
\end{tabular}


usamos la panza"; "yo no entendí bien la consigna, me perdí, a mí me llamó la atención que aunque no fue la consigna no hablaban en el grupo, así que bueno yo hacía lo que decía A.";"fue muy llamativo cuando dijiste "tienen que estar felices" y todos estaban tan concentrados que no le salía, estaban todos re serios"

Mientras algunos seguían debatiendo sobre lo vivenciado, una joven se acerca ingresa al lugar intentando no interrumpir, se queda parada hasta finalizar la actividad, luego la integramos a la ronda y a un grupo.

Cerramos la actividad con una pregunta final: "¿QUÉ NO QUIERO DEJAR CAER?" entre las respuestas: "la niñez", "merendero", "crear un espacio de juego entre los niños y adultos", "los vínculos", "no dejar caer a los adultos que tienen el entusiasmo y el interés", "no dejar caer espacios que son significativos para los jóvenes, crearlos", "no dejar caer a los amigos". había hecho. Observo como en ambos grupo sucede lo mismo cuando el globo pasa los límites de la cintura, lo dejan caer. No dejándose llevar y pasar al otro nivel, es decir, "si estoy parado y el globo pasa mi cintura, puedo agacharme o acostarme" rompiendo con el estar siempre parado, sin embargo a ni uno pareció importarle.

En el momento de reflexión expresé lo que sentía, pero me resonaron las palabras de una adolescente llamada M., que rescató los espacios y los adultos que hacían por los jóvenes. Me emocionó su firmeza.

Es interesante resaltar como en este tipo de actividades somos todos una unión de ese "aquí y ahora" espacio donde no se remarcan las diferencias culturales, de edad, nivel de escolarización, un espacio donde logramos convivir, tolerar y promover la escucha y la palabra.
Colectividad, reflexión colectiva. el trabajo en equipo", "el entusiasmo", "la diversión"

Disponibilidad para el uso del cuerpo, entrega en el juego.

Concepciones de mundo. Intereses personal $y$ colectivo.

Estrategias

valoradas como eficaces.

Diálogo. Espacio simbólico que habilita tolerar colectivamente la realidad.

Habilitación de la palabra joven. Escucha respetuosa. Horizontalidad

Cuadro 2 (parte del registro realizado del encuentro 13 de mayo de 2017)

\begin{tabular}{|l|l|lr|}
\hline Registro & Implicación & Categorización \\
\hline Se comunica la tercera actividad. & Nuevamente observo & Dinámica del \\
Elaborar/desarrollar un sketch en el & compromiso, involucramiento & espacio y la \\
que se represente ¿cómo está el & escucha atenta, discusión al & actividad. & \\
barrio/provincia/país?. Es necesario & interior de los grupos. Hay clima & Dinámica de \\
repetir la consigna, en cada grupo & distendido pero de mucho & grupo: roles \\
para que los integrantes & intercambio, los niños que asisten & \\
comprendan. & altaller juegan y entran y salen & Escuela como \\
Se evidencian diferentes estrategias & sin que eso interrumpa el & institución \\
en cada grupo: ¿cuántos integrantes & desarrollo de las actividades. & \\
son del barrio? (4/8 en uno y 5/8 en & Noto que en los grupos hay & Necesidades, \\
otro). Detallo algunos de los puntos & diferencias en la participación de & realidad social, \\
que oí en cada grupo: & las personas que forman parte del & contexto de crisis \\
Grupo 1: "construyeron una escuela & grupo de EP: en un grupo hay una & nacional, \\
\hline
\end{tabular}




\begin{tabular}{|c|c|c|}
\hline 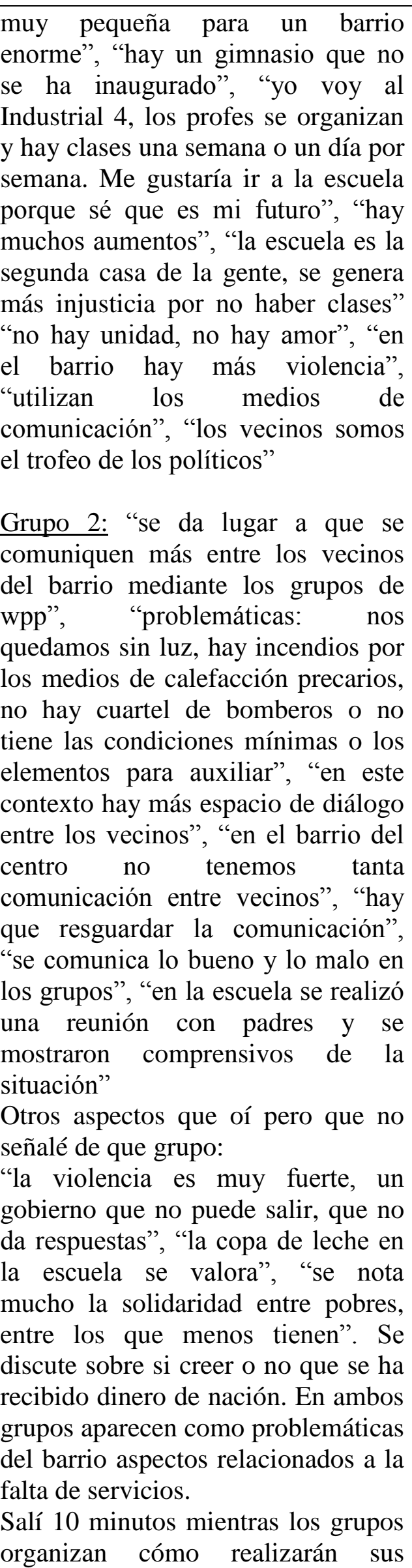 & $\begin{array}{l}\text { participación más activa de los } \\
\text { "organizadores" en el momento } \\
\text { de la descripción o discusión } \\
\text { sobre la situación del barrio, } \\
\text { provincia, país (me pregunto si } \\
\text { esto no dificulta u obtura la } \\
\text { participación de los "asistentes" o } \\
\text { si por el contrario esto habilita la } \\
\text { "horizontalidad" o la pertenencia } \\
\text { al grupo de teatro comunitario del } \\
\text { barrio sin distinguir entre } \\
\text { "organizadores/asistentes"); en } \\
\text { otro grupo la participación } \\
\text { protagónica de "organizadores" } \\
\text { se da al momento de pensar o } \\
\text { proponer las formas de } \\
\text { representación (creo que esto se } \\
\text { evidenció en las presentaciones } \\
\text { que realizaron los grupos, una } \\
\text { más metafórica y otra más } \\
\text { explícita) gara } \\
\text { Me conmueve escuchar la } \\
\text { necesidad de volver a la escuela, } \\
\text { o sea de volver a "nuestra" } \\
\text { escuela. Son alumnos y padres de } \\
\text { MI escuela los que manifiestan el } \\
\text { deseo, la necesidad de regresar al } \\
\text { colegio. Deseo y necesidad que } \\
\text { comparto, iicuántas ganas de } \\
\text { expresar mis ganas de } \\
\text { encontrarnos en los recreos, en } \\
\text { los pasillos me dieron!!. } \\
\text { Me impresiona todo lo que "ha } \\
\text { cambiado" el ambiente y el lugar } \\
\text { a mi regreso, se continúa } \\
\text { evidenciado compromiso e } \\
\text { involucramiento en la actividad } \\
\text { pero observo además ansiedad y } \\
\text { ganas de mostrar lo que han } \\
\text { producido. }\end{array}$ & $\begin{array}{lr}\text { provincial } & \text { y } \\
\text { local. } & \\
\text { Espacio } & \\
\text { simbólico. } & \\
\text { Percepción de la } \\
\text { realidad. }\end{array}$ \\
\hline
\end{tabular}




\begin{tabular}{|c|c|c|}
\hline $\begin{array}{l}\text { representaciones. } \\
\text { Al regresar los grupos se han } \\
\text { separado de espacios, unos en la } \\
\text { cocina y otros en el sum. Han } \\
\text { seleccionado objetos que utilizarán } \\
\text { para personificar o enriquecer las } \\
\text { representaciones que realizarán. }\end{array}$ & & \\
\hline $\begin{array}{l}\text { Se desarrollan las presentaciones } \\
\text { Representaciones: un grupo decide } \\
\text { representar mediante una alegoría o } \\
\text { metáfora, otro mediante el desarrollo } \\
\text { de situaciones de la cotidianeidad. } \\
\text { Ambas representaciones incluyen la } \\
\text { figura del estado gobierno (la } \\
\text { parka/bruja-la gobernadora). En } \\
\text { ambos grupos hay explicitación de } \\
\text { los reclamos que la ciudadanía y los } \\
\text { trabajadores hacen al estado (desde } \\
\text { lo metafórico-en representaciones de } \\
\text { actividades cotidianas). En ambos } \\
\text { grupos se muestra la unión de } \\
\text { quienes reclaman, en uno de los } \\
\text { grupos se representa a ciudadanos } \\
\text { que se muestran indiferentes al } \\
\text { reclamo o que no apoyan el mismo. } \\
\text { Ambos grupos muestran al estado } \\
\text { como ciego, dando la espalda al } \\
\text { pueblo, no dando respuestas o } \\
\text { castigando al pueblo. Ambas } \\
\text { representaciones muestran una } \\
\text { posible solución del conflicto. } \\
\text { Durante ambas presentaciones el } \\
\text { grupo "espectador" se muestra } \\
\text { respetuoso, concentrado y atento a la } \\
\text { representación. a }\end{array}$ & $\begin{array}{l}\text { Siento gran expectación respecto } \\
\text { de cuáles serán los sketchs y } \\
\text { cómo resultarán las } \\
\text { representaciones. } \\
\text { Me sorprende cómo resuelven o } \\
\text { logran contar lo discutido al } \\
\text { interior de los grupos mediante el } \\
\text { sketch. iQué poderoso es el } \\
\text { teatro! iQué necesario se hace ser } \\
\text { otros o uno mismo actuando } \\
\text { diferente o logrando, finalmente!, } \\
\text { resolver situaciones que nos } \\
\text { agobian, que nos atraviesan. } \\
\text { Liberador, enriquecedor, } \\
\text { transformador (de uno mismo en } \\
\text { principio) es el uso del cuerpo, la } \\
\text { vivencia, el pronunciamiento de } \\
\text { la palabra, el desarrollo de la } \\
\text { acción (perdón si es delirante } \\
\text { esto!, pero todo eso me generó) } \\
\text { Buenísimo haber puesto a } \\
\text { disposición de los grupos } \\
\text { materiales para } \\
\text { apoyar/acompañar a las } \\
\text { representaciones. Creo que todos } \\
\text { los encuentros deberíamos llevar } \\
\text { materiales, objetos, etc. }\end{array}$ & $\begin{array}{l}\text { La escena } \\
\text { permite sentirse } \\
\text { y ser autores de } \\
\text { la propia } \\
\text { experiencia, } \\
\text { evidenciando a } \\
\text { través del } \\
\text { dramatizar } \\
\text { colectivamente } \\
\text { Estado como } \\
\text { indiferente frente } \\
\text { a las necesidades } \\
\text { de la comunidad, } \\
\text { de los vecinos y } \\
\text { las vecinas de } \\
\text { este Barrio. } \\
\text { Problematización } \\
\text { y reflexión. }\end{array}$ \\
\hline
\end{tabular}

Son muchas las líneas de interpretación y análisis que se abren desde la lectura detenida de los registros. Cuando nos centramos en la pregunta realizada por la coordinación de "¿qué no quiero dejar caer?" entre las respuestas surgieron cuestiones como "la niñez", "merendero", "crear un espacio de juego entre los niños y adultos", "los vínculos", "no dejar caer a los adultos que tienen el entusiasmo y el interés", "no dejar caer espacios que son significativos para los jóvenes, crearlos", "no dejar caer a los amigos". Esto muestra que pese a las complejas situaciones de vulnerabilidad social en las que viven estos y estas vecinos y vecinas, hay cierta esperanza o rescate de lo comunitario como una vía o camino posible para atravesar esta realidad que los/as afecta.

Se analizó desde este y otros registros de estos talleres como manifiestan los y las participantes en las diversas representaciones la figura del Estado-gobierno, la gobernadora 
como la parka/bruja-muestran al Estado como ciego, dando la espalda al pueblo, y comentan visibilizado a través de expresiones como: "los vecinos somos el trofeo de los políticos", dejando en claro cómo el Estado da respuestas castigando al pueblo. Frente a estas situaciones violentas presentan posibles soluciones como el sentimiento de esperanza de que el cambio puede lograrse con unidad, de que la unidad puede hacer el cambio. Por otro lado lo que anhelan es que el pueblo se una, surge la idea de jugar a ser otros/as, a imaginar otras realidades posibles, ser formadores de nuestro propio destino.

Estas composiciones expresivas, escénicas son en sí mismas significativas, reflejando a través de la entrega de las y los participantes, su implicación activa , comprometida, crítica, poniendo el cuerpo representando entre otras cosas el tapado de ojos de quien interpretaba el Estado en un sentido ausente que aparece como un punto transversal que afecta a este barrio de manera más visible en relación a otros sectores, las viviendas en situaciones muy precarias dado a que en muchos casos éstas no cuentan con los servicios básicos, etc.

La descripción del barrio podríamos resumirla como una zona que se encuentra en condiciones de vulnerabilidad social donde los vecinos buscan resistir las duras condiciones objetivas de vida cargadas además de desarraigo y marginación. En referencia a sus características, las calles son de arena y piedra sin asfaltar, con falta de acondicionamiento, con sectores inundables y grandes baches que dificultan la circulación, ingreso y egreso, situación que se agrava por las hostiles condiciones climáticas en la Patagonia Austral vientos fuertes, temperaturas por debajo de cero grados, escarcha y nevadas en época invernal. Otras problemáticas graves identificadas en el barrio que afectan la calidad de vida de los vecinos son la falta de tratamiento de efluentes cloacales, el uso de pozos negros que constituyen focos de infección que afectan tanto al agua para consumo humano y para riego; los criaderos de porcinos y ovinos que producen olores, faena clandestina y aguas servidas que afectan las napas freáticas transmitiendo enfermedades. Respecto del suministro de energía eléctrica, es insuficiente; abunda el tendido indiscriminado e irregular de cableado eléctrico y el alumbrado público escaso. Las condiciones de provisión de gas son precarias y varios sectores no cuentan con gas natural, utilizando gas envasado sumamente costoso y necesario dado las condiciones climáticas en esta región. Otras dificultades son la gran cantidad de perros sueltos que atacan a los transeúntes, ausencia de forestación y la falta de espacios verdes recreativos, falta de tratamiento de residuos domiciliarios, degradación sonora, del aire y visual por cercanías de tránsito pesado y la presencia de mini basurales, vehículos abandonados y acopio de materiales en la vía pública (Ramón, 2018)

Esta caracterización del barrio realizada por una compañera del Equipo de Educación Popular que está en proceso de escritura de su tesis doctoral, se ve nutrida por los aportes de los análisis de los distintos talleres de los cuales todos y todas formamos parte. Hemos vivenciado de esta forma al teatro comunitario permitiendo-le a la comunidad, a hablar a través de la reflexión colectiva ayudando a crear un sentido de identidad, y fortaleciendo así los espacios de denuncia y anuncios colectivas. Volvemos a la idea de un "nosotros/as" que denuncia y que mira críticamente el contexto, el Estado, y la realidad que los/as y nos atraviesa.

Al respecto, no podemos dejar de mencionar que estas representaciones, estas denuncias de estos y estas vecinas, se enmarcan no sólo en una feroz crisis nacional y regional, sino específicamente en una gran crisis política, social, económica, sanitaria y educativa de la provincia de Santa Cruz. Desde el segundo semestre de 2016 el ejecutivo provincial comienza con prolongadas demoras en los pagos de salarios a trabajadores estatales y jubilados que 
continúan hasta la actualidad. Pero el retraso en los pagos también afecta a proveedores del Estado, las inversiones en infraestructura básica, insumos mínimos en Educación, Salud y Seguridad, y la mínima erogación en bienes de capital. Durante los últimos años se ha producido un deterioro muy importante en el sistema educativo: suspensión de clases por problemas edilicios, por retención de tareas por falta de pago de salarios, por paros docentes (ADOSAC) y de ATE que agrupa a sectores responsables de la limpieza de las escuelas. Sólo basta mencionar como ejemplo las siguientes cifras: durante el 2016 los días de clase fueron 90, y durante el 2017 los días de paro superaron los 110, comenzando el ciclo lectivo recién en el mes de agosto.

Es frecuente escuchar en los talleres realizados en la Escuela durante el período señalado a los/as vecinos/as y actores de este establecimiento expresiones como: "está la nostalgia de volver a la escuela también", "ganas de volver al barrio y a la escuela", "la copa de leche en la escuela se valora", "vine porque necesitaba bajar a la realidad". Evidenciando de esta manera la importancia de este espacio de pertenencia. Se puede ver en las diversas actividades donde utilizan expresiones como: "la escuela es la segunda casa de la gente". Los talleres de teatro comunitario se constituyen como una oportunidad donde se puede poner en palabras y visibilizar las problemáticas que los y las atraviesan que muchas veces se encuentran naturalizadas por el contexto, el Estado y por ellos mismos. Y finalmente cada concurrente logra poner en palabra lo vivenciado en los talleres luego de pensar soluciones colectivas frente a las vivencias de violencia que viven en este barrio. Pusieron de manifiesto el deseo de "poder venir para compartir", otros definieron los talleres como un espacio movilizador", lo definieron como lugar de "participación/poner el cuerpo/placentero", "lucha/piquete/equilibrio entre realidad lúdico expresar/jugar/jugarse".

Al finalizar las dramatizaciones que despliegan los y las vecinas, surge la reflexión en la que aparece la resolución de las situaciones anhelando la unión del pueblo/del barrio. Los finales representados muestran cierta esperanza de que el cambio pueda lograrse mediante la unidad, que la unidad de los vecinos puede hacer el cambio. Entonces, podemos inferir que se construye y circula la unión como cuestión necesaria al pensar algunas opciones de transformación de aspectos de las condiciones desfavorables del contexto barrial y social en la que vivimos. Las reflexiones de los participantes acerca de cómo vivenciaron estas experiencias hace referencia a la posibilidad de cambiar la mirada, de compartir con otros, de re pensar se, de co construir, de crear y vivenciar un espacio de una instancia colectiva que los acerca, los contiene y los reposiciona frente a la lectura del contexto.

En referencia al campo de la psicopedagogía, tanto la Educación Popular como el Teatro Comunitario y el acercamiento a prácticas de Investigación Acción Participativa permiten a intervenir desde la generación de espacios de participación social en los cuales se logre promover el diálogo, la comunicación, colaborando en procesos de concientización. Esto se pudo ver claramente en todos y cada uno de los talleres de Teatro Comunitario en los cuales los vecinos y las vecinas en las distintas actividades propuestas por el equipo mostraron entusiasmo, interés, esperanza y deseo por participar, como así también manifestaron en los diversos momentos de reflexión lo senti pensado colectivamente.

Consideramos que para conformar y definir estrategias de intervención psicopedagógicas ajustadas al campo comunitario se torna necesario conocer, indagar e investigar problemas, necesidades y/o prioridades de los sectores con los cuales se interviene y es por ello que la IAP se torna una gran herramienta metodológica y política de intervención para investigar junto con la comunidad, problematiza y pensar, co-pensar procesos de transformación de esta 
realidad. Siguiendo con el eje en la mirada psicopedagógica y poniendo énfasis en su objeto de estudio, pudimos evidenciar en los diversos encuentros de Teatro Comunitario con los y las vecinas del barrio formas claras del crecimiento del grupo y de aprendizajes colectivos en el reconocimiento de sus necesidades, en la formulación de conclusiones e interpretaciones

En este sentido y a través de la experiencia de los talleres pudimos vivenciar junto con los vecinos y las vecinas del barrio momentos reflexivos, de aprendizaje colectivo como mencionamos anteriormente y es desde esta experiencia que entendemos al aprendizaje como un proceso complejo que se da a lo largo de toda la vida, es un proceso debido a que el mismo no es lineal sino que es dinámico y complejo porque involucra al sujeto en todas sus dimensiones, al sujeto en cuerpo, en inteligencia, al sujeto en tanto sujeto activo, partícipe de este proceso. El aprendizaje es siempre un proceso de construcción simbólico de las vivencias propias del sujeto en un contexto sociocultural e histórico particular en el cual está inmerso. Aprender es un proceso de autoría de conocimiento, de pensamientos, de construcción subjetiva en constante interacción con otro/a y con el medio. Es desde una mirada social e integral que entendemos que no existe proceso educativo ni de aprendizaje que no sea social ni contextualizado. De allí la importancia de la sistematización que aún seguimos construyendo de estos talleres.

El aprendizaje es un proceso vivencial, experiencial. Podemos pensar que el aprendizaje a lo largo de todas las etapas evolutivas, en muchos de los momentos de nuestra vida se realiza a través de un sostén, y es desde esta concepción a través de esta experiencia en particular de trabajo en territorio como podemos evidenciar este aprendizaje colectivo, esta construcción en coautoría como un aprendizaje sostenido. Tal y como nos dice Alicia Fernández en toda su obra tanto los aspectos vinculados al amor como así también al sostén, son una condición necesaria para que cualquier aprendizaje sea posible. Desde esta perspectiva el aprendizaje es un espacio de encuentro que da lugar a un "nosotros" a una puesta en escena de la realidad que los sujetos viven, que atraviesa su vida cotidiana, que afecta sus condiciones concretas de existencia. Es desde este espacio que se abre la posibilidad al pensar, repensar, reflexionar, problematizar, visibilizar, denunciar y anunciar con ese otro esta realidad que se muestra como injusta. Es a través de un proceso de construcción colectiva que se generan espacio de intercambio, de aprendizaje colectivo que dan lugar a pensar a aprehender colectivamente, a construir en coautoría.

Los sujetos aprenden en tanto existe un deseo como motor de este proceso. Este deseo desde estos talleres de teatro comunitario puede visibilizarse como deseo de denunciar la realidad en la que se vive, de apropiarse de diversas herramientas para generar un cambio sobre esta realidad que se presenta injusta, violenta. Adherimos a las concepciones de Alicia Fernandez (1993) cuando menciona que en la enseñanza y el aprendizaje intervienen al menos cuatro niveles, entre ellos: el organismo, el cuerpo, la inteligencia y el deseo. El aprendizaje se da en un vínculo. Estos niveles están en un proceso dialectico con el afuera. En este sentido la Educación Popular, la IAP y el Teatro Comunitario implican la participación, poner el cuerpo. El cuerpo tiene un lugar en el aprendizaje. El cuerpo permite sentir y pensar, sentipensar con otros. El cuerpo permite simbolizar a la vez que esta transversalizado por el deseo. El cuerpo permite el aprendizaje por medio de la acción y luego de la simbolización y representación. El cuerpo a la vez que aprendemos nos permite "enseñar" - es decir, mostrar- enseñarnos.

Siguiendo con el anclaje en los aportes del campo psicopedagógico a este tipo de propuesta socio comunitaria, Alicia Fernández (2000) menciona que el adjetivo clínica hace referencia a una postura, a un posicionamiento el cual forma parte del psicopedagogo/a -si me refiero únicamente al campo que nos compete- En este sentido es fundamental entender que la 
mirada está puesta en el sujeto, teniendo en cuenta que es este sujeto quien sabe lo que le pasa. La clínica deja emerger el plano de la subjetividad, la cual requiere de un análisis permanente de los signos y señales, que el sujeto muestra.

\section{CONCLUSIONES GENERALES}

Dentro de este marco teórico de las pedagogías criticas propuesto por la EP, analizamos -este analizar conjuntamente implica la participación real- junto a algunos/as integrantes de la Escuela y vecinos y vecinas del Barrio San Benito ciertas experiencias pedagógicas que escapan al formato tradicional, bancario, reproductor de la educación. Elegimos trabajar desde la integralidad de la Educación Popular, la IAP y el Teatro Comunitario, debido a que responden a nuestro posicionamiento crítico, en tanto son instrumentos de lucha social que involucra la construcción conjunta. Incluye la participación de los/as diversos/as actores, y esta participación es siempre activa. Los sujetos son protagonistas, y como tales son quienes expresan sus inquietudes, necesidades, enojos, etc. Esta elección que no es sólo política, pedagógica, metodológica, sino también ética y estética, implica no sólo la problematización de la realidad cercana, sino también la posibilidad de escenificar otras realidades posibles, deseables, escenificación de posibles transformaciones focalizadas que contribuyan a un buen vivir.

Creemos importante asentar que el teatro comunitario permite poner el cuerpo como medio de expresión de necesidades, deseos, anhelos, y como vehículo para "hacer hablar a la comunidad", poner en palabra aquello que inquieta, molesta, perjudica generando de forma colectiva posibles acciones transformadoras de esta realidad que intentamos visibilizar. El teatro comunitario y la educación popular ligada a la IAP llaman a la reflexión a partir del discurso y el diálogo, son una apuesta por lo comunitario y transformador en tanto concebimos que son dos miradas inclusivas, productoras de conocimiento. Intentamos dejar explícito en este escrito cómo, desde el espacio de teatro comunitario -espacio de producción e intercambio con el/la otro/a- se crean aprendizajes colectivos, a través de los cuales se cocontruyen cosas nuevas, conocimientos y reflexiones compartidas acerca de esa realidad que se vive. Desde los aportes de la formación de grado de la becaria, coautora de este escrito, podemos enriquecer este análisis, afirmando que tanto la IAP, como la Educación Popular y el Teatro Comunitario son prácticas, elecciones orientadas hacia la creatividad y la participación social. Conllevan un proceso gradual de aprendizaje, de co-aprendizaje o aprendizaje colectivo, el cual surge a partir de la reflexión colectiva del grupo.

Desde esta mirada y a partir de la experiencia del trabajo de campo en los talleres de teatro comunitario se pudo observar que el grupo es sostén de lo individual. Estos instrumentos de lucha social permiten la construcción de nuevas subjetividades, más críticas y reflexivas, brindando un espacio de pertenencia que les/nos da seguridad. Aparece la motivación mutua con la presencia del otro, la esperanza, el deseo de generar cambios, de repensarse. El poder descubrir por medio de la reflexión conjunta y la desnaturalización de sus situaciones cotidianas da lugar a la conformación de conciencia crítica colectiva. La transformación de sí mismos genera y posibilita un cambio en el entorno

En lo que respecta al área de la psicopedagogía, el y la psicopedagogo/a como profesional que se vincula no solo al abordaje individual sino también a la acción grupal y social supone y requiere interrogarse sobre cómo se relaciona lo educativo con lo social. Sería interesante destacar desde esta perspectiva que la psicopedagogía en el campo sociocomunitario debe dirigirse por un lado a indagar acerca de cómo estas problemáticas impactan en la capacidad del proceso de aprendizaje del sujeto y debería poder intervenir en las áreas socio 
comunitarias como así también psico educativa y socio afectivas aportando desde la prevención. En este sentido la intervención psicopedagógica debe estar dirigida a codificar y decodificar tanto como anunciar y denunciar la propia realidad en la cual se encuentran inmersos los sujetos con los y las que trabajamos para lograr conjuntamente contribuir a la transformación.

Coincidimos con las concepciones Freirianas al entender al sujeto como relacional, tanto con otros/as como con la realidad, el ambiente, el mundo, la naturaleza, consigo mismo/a desde su reflexión-acción. El abordaje comunitario nos invita a pensar en un /a psicopedagogo/a que posea herramientas vinculadas al ámbito social, que tenga una mirada crítica sobre la realidad, una concepción política, ética y estética de hombre y de mundo.

La psicopedagogía debe permitir en estos contextos de crisis reflexionar y aportar a la comunidad científica acerca de las posibilidades de intervención específica en ámbitos comunitarios desde la perspectiva de la Educación Popular y la Investigación Acción Participativa. El proceso educativo se constituye así en vivencia y experiencia activa del sujeto concebido como autor-recreador. Podría tomar como herramienta de la Educación Popular el hecho de que es una propuesta educativa de apertura, que permite el dialogo como estrategia para alcanzar el aprendizaje, legitima la diferencia, el rescate del sujeto en sus contextos y sus aprendizajes, permite que el sujeto sea protagonista del proceso educativo entendido como práctica social que no sólo reproduce, sino también produce, habilita, transforma.

\section{BIBLIOGRAFÍA}

ANTEQUERA, M.F; CHEVASCO, M; CRAPARO, R; SERRA M. F Articulación social y prácticas sociocomunitarias. Un desafío para la Universidad Pública Rosario UNR 2015.

APPLE, M: Ideología y currículum, Madrid, Akal, 1981.

ARIAS, P. 2013. De la indefensión a la impotencia. Una lectura psicopedagógica sobre los alumnos y maestros en contextos vulnerables, Río Gallegos, Argentina: Universidad Nacional de la Patagonia Austral. https://doi.org/10.17227/01234870.41folios51.68

BIDEGAÍN, Marcela (2007) Teatro comunitario. Resistencia y transformación social, Editorial Atuel, Buenos Aires.

BOAL, A. 1970. Otro teatro posible. Técnicas latinoamericanas de teatro popular. Falta ciudad y país, El Rebozo

CIENFUEGOS, MICHNIUK Y OTROS: Bienales del V Encuentro de Investigadores de la Patagonia Austral: "Análisis crítico de los sentidos que tienen diversas experiencias pedagógicas alternativas que transcurren por los bordes de una escuela del Barrio San Benito de Río Gallegos. Aportes de la EP y la IAP” ISBN 978-987-3714-56-6 1 Ed. https://doi.org/10.29057/estr.v1i1.1356

CIENFUEGOS, MICHNIUK y otros Libro de resúmenes Proyectos de Investigación 20142018 Universidad Nacional de la Patagonia Austral ediciones UNPA edita "La educación popular, una alternativa político-pedagógica para la problematización y transformación de nuestras prácticas. Sistematización participativa de experiencias educativas y socio-comunitarias en la ciudad de Río Gallegos”. ISBN 978-987-371454-2. https://doi.org/10.2307/j.ctvr33d8f.8 
CIENFUEGOS, MICHNIUK y PUCHETA "Problemáticas educativas: formación e intervención desde una perspectiva crítica": el desafío de la integralidad desde un programa institucional de la UNPA UARG" Primer Congreso Internacional de Educación e Inclusión desde el Sur organizado por el Municipio de Río Grande y UNISAL Río Grande, Tierra del Fuego 18,19 y 20 de octubre de 2018. https://doi.org/10.35537/10915/74979

DE SOUZA SANTOS, B. (2010) Descolonizar el saber, reinventar el poder. Uruguay. Trilce

DE SOUSA SANTOS, B: Los nuevos movimientos sociales, Rev. OSAL $\mathrm{N}^{0}$, Buenos Aires, CLACSO, 2001

DE SOUZA SANTOS, B. (2010) Refundación del estado en América Latina: Perspectivas desde una epistemología del sur. México: Siglo XXI. https://doi.org/10.1177/0268580914524332b

Diapositivas y apuntes del Seminario taller de postgrado: "La investigación acción participativa (IAP) como modo de hacer ciencia de lo social" (2017) Docente Responsable: Dra. Sandra Llosa

ETCHEGOYEN, M. A (2006) Educación y ciudadanía. La búsqueda del buen sentido en el sentido común BsAs La Crujía

FERNANDEZ A. (1989). La inteligencia atrapada. Editorial Nueva Visión, Buenos Aires. República Argentina.

FERNANDEZ A. (2000). Los idiomas del aprendiente. Nueva Visión SAIC. Buenos Aires, República Argentina.

FERNANDEZ A. (2000). Poner en juego el saber. Nueva Visión. Buenos Aires, República Argentina

FERNANDEZ A. (2001). Psicopedagogía en psicodrama. Nueva Visión. Buenos Aires. República Argentina.

FREIRE, P. (1988) Pedagogía de la esperanza. Un reencuentro con la pedagogía del oprimido. México. Siglo XXI

FREIRE, P. (1970) Pedagogia del oprimido. Montevideo. Tierra Nueva.

FREIRE, P. (1973) ¿Extensión o Comunicación? La concientización en el medio rural. Buenos Aires. Siglo XXI

FREIRE, P FALS BORDA, O. (2017). Aportes. Educadores populares. Bogotá Dimensión educativa.

GARCES, M: Educación Popular y movimientos sociales, Rev. La Piragua Nº 20, CEAAL, 2004

GHISO, A (1998) "De la práctica singular al diálogo con lo plural. Aproximaciones a otros tránsitos y sentidos de la sistematización en épocas de globalización." En La piragua. Revista Latinoamericana de Educación. Sistematización de prácticas en America Latina. \# 16 1999. https://doi.org/10.2307/j.ctvr33d8f.8

GHISO, A (2004) "Entre el hacer lo que se sabe y el saber lo que se hace" en Sistematización de experiencias. Propuestas y debates. Dimensión educativa. Bogotá.

GIANNONE, A. y GOMEZ, M. (2007) Psicopedagogía... a la distancia. Edición del Autor. https://doi.org/10.5093/ed2010v16n1a8

GRAMSCI, A: La alternativa pedagógica, Mexico Fontamara, 2007

GRAMSCI, A: Notas sobre Maquiavelo, sobre política y sobre el Estado Moderno, Buenos Aires, Nueva Visión, 1972

HERNANDEZ, I (comp): Saber popular y educación en América Latina, Buenos Aires, Búsqueda - CEAAL, 1985

HILLER, OUVIÑZ; RIGAL Y SUAREZ Gramsci y la educación: pedagogía de la praxis y políticas culturales en América Latina BsAs noveduc 2011 
HÖHNE-SPARBOTH, Y. FAJARDO, J.B Y ROMERO SÁNCHEZ, A. (2015) Danzando la resurrección de los cuerpos. Rutas de autocuidado y autosanación energética. Bogotá, Colombia: Códice Ltda.

HOLLIDAY, O. (2017) La sistematización de experiencias: prácticas y teoría para otros mundos Posibles. Primera edición colombiana. Cinde.

HUIDOBRO, R.A. ELSEGOOD, L. GARAÑO, I. Y HARGUINTEGUY, F (2015). Universidad territorio y transformación social. Buenos Aires, Argentina:Undav. https://doi.org/10.35428/cds.v0i1.12

JARA, O. (2017) La sistematización de experiencias: prácticas y teoría para otros mundos Posibles. Primera edición colombiana. Cinde.

JUÁREZ, M. P. Aproximaciones a una Psicopedagogía Comunitaria: reflexiones, aportes y desafíos. (2012) [archivo PDF] Pesquisas e Práticas Psicossociais, 7(2), São João delRei, julho/dezembro. Recuperado de https://ufsj.edu.br/portal2repositorio/File/revistalapip/Volume7_n2/Juarez,_Maria_Paula.pdf

KANTOR, D, Variaciones para educar adolescentes y jóvenes. BsA Del Estante (2008)

KAPLAN, MARTINI Y OTROS. Revista Novedades Educativas. Octubre (2015) Experiencias de inclusión educativa. Necesidades emocionales de niños y adolescentes. Novedades Educativas.

LLIANAS, P (2011) Variaciones sobre la forma escolar: límites y posibilidades de la escuela media Rosario Homo Sapiens

LLOSA, S. (2000). La sesión de retroalimentación de la investigación como espacio de construcción colectiva de conocimientos: una experiencia en La Ribera de Quilmes. En E. Litwin y otros, Educación, Crisis y Utopías. Análisis político y propuestas pedagógicas. Tomo I (pp. 298-306). Bs. As.: UBA - Aique. https://doi.org/10.19083/ridu.3.19

LLOSA, S. (2012). La praxis pedagógica sociocomunitaria desde la perspectiva de la Educación Popular y la Investigación Participativa: desafíos a la luz de experiencias. Conferencia. Jornada Académica en la Segunda Edición de la Semana Freireana. Río Grande, Tierra del Fuego, set. 2012. https://doi.org/10.35537/10915/49538

LLOSA, S. (2000). La sesión de retroalimentación de la investigación como espacio de construcción colectiva de conocimientos: una experiencia en La Ribera de Quilmes. En AAVV: Educación, Crisis y Utopías. Análisis político y propuestas pedagógicas Tomo I (pp. 298-306). Buenos Aires: UBA - Aique. https://doi.org/10.1016/j.riem.2017.01.120

MARTINIS, P. Y RECONDO, P (comps): Igualdad y educación. Escrituras entre (dos) orillas, Buenos Aires, Del Estante, 2006

MEJIA, MR: Reconstruyendo la transformación social: movimientos sociales y educación popular, La Paz, Cebiae, 1998

MEJIA, M.R. y AWAD, M: Pedagogías y metodologías en educación popular, Bogotá, CINEP, 1998, mimeo.

NUÑEZ HURTADO, C: La revolución ética, Guadalajara, IMDEC. 1998

RAMÓN, M "Talleres de teatro comunitario en una escuela de un barrio en Rio Gallegos" Ponencia presentada en el Primer Congreso Internacional de Educación e Inclusión desde el Sur organizado por el Municipio de Río Grande y UNISAL Río Grande, Tierra del Fuego 18, 19 y 20 de octubre de 2018. https://doi.org/10.3989/pirineos.2016.171008

RAMÓN, M. Tesis doctoral en proceso "Procesos culturales y educativos en contextos de vulnerabilidad social. El caso del Barrio San Benito en Rio Gallegos de 1990 a 2017". Lic. Moira Silvana Ramón UNPA. https://doi.org/10.18172/con.605 
RIGAL, L: Sobre el encuadre de los procesos de sistematización, Buenos Aires, CIPES. 1999, Documento de trabajo

RIGAL, L: El sentido de educar, Buenos Aires, Miño y Dávila, 2004

RIGAL, L: Reinventar la Escuela: Una Perspectiva desde la Educación Popular, en van Dam, A., Martinic, S. y Peter, G.(comps): Cultura y Política en Educación Popular: principios, pragmatismo y negociación, La Haya, CESO, 1995. https://doi.org/10.1787/9789264205178-es

RIGAL, L., VILLAGRA, M. y ZINGER, S: Movimientos sociales y educación popular: Barrios de Pié en Jujuy, op. cit.

SCHER, E (2010) Teatro de vecinos. De la comunidad para la comunidad, Editorial del Instituto Nacional del Teatro, Buenos Aires. https://doi.org/10.22370/panambi.2016.2.534

SIRVENT M.T Y RIGAL, L. (2012). Investigación Acción Participativa. Un desafío de nuestros tiempos para la construcción de una sociedad democrática. Colección Proyecto Páramo Andino. Quito, Ecuador.

SIRVENT, MT: Ejercicio para los trabajos prácticos, Buenos Aires, FFYL - UBA, 2003, Ficha de cátedra

SIRVENT, M.T. et al: Revisión del concepto de Educación No Formal, Buenos Aires, Depto. de Ciencias de la Educación, FFYL - UBA, 2009, Documento de Trabajo. https://doi.org/10.25145/c.educomp.2018.16.018

SIRVENT, MT: Cultura popular y participación social, Una investigación en el barrio de Mataderos, Buenos Aires, Miño y Dávila, 2004

SIRVENT, M. T. (2010) La Investigación Acción Participativa y la educación Popular: su encuadre pedagógico. En Hillert, F., Ameijeiras, M.J. y Graciano, N. (comp.): La mirada pedagógica para el siglo XXI: teorías, temas y prácticas en cuestión. Publicación de la Maestría: "Pedagogías críticas y problemáticas socioeducativas". Bs. As.: Facultad de Filosofía y Letras - UBA / Ediciones Buenos Libros. https://doi.org/10.35376/10324/37920

SIRVENT, M.T. (2010). La Investigación Acción Participativa y la Animación SocioCultural. Su papel en la Participación Ciudadana. Revue Internationale Animation, territoires et pratiques socioculturelles $\mathrm{N}^{\circ} 1$. Université du Québec à Montréal, Faculte de communication. Montreal, Canadá

SIRVENT M.T y RIGAL, L. (2012). Investigación acción participativa. Un desafío de nuestros tiempos para la construcción de una sociedad democrática. Colección Proyecto Páramo Andino. Proyecto Regional. Quito-Ecuador.

SIRVENT, M.T. (2010). Relaciones de teoría y metodología en investigación educativa. Revista Controversias y concurrencias Latinoamericanas $N^{\circ} 3$, Pp 129-158. Buenos Aires: Editorial Asociación Latinoamericana de Sociología.

Proyecto de Extensión "Educación Popular y teatro comunitario. Una experiencia en el Barrio San Benito de Río Gallegos" (Acuerdo de Unidad 656/16)

Proyecto de Investigación 29/A390 UNPA UARG “Análisis crítico de los sentidos que tienen diversas experiencias pedagógicas alternativas que transcurren por los bordes de una escuela del barrio San Benito de Río Gallegos. Continuidades y resistencias de la cultura hegemónica. Aportes y abordajes desde la Educación Popular y la Investigación Acción Participativa”. 